OCEANS 2015 - Genova. ITALY, MAY 18-21, 2015

Pages 1-10

http://dx.doi.org/ 10.1109/OCEANS-Genova.2015.7271715

http://archimer.ifremer.fr/doc/00349/45998/

(C) 2015 IEEE - All rights reserved

\title{
Biofouling protection by electro-chlorination on optical windows for oceanographic sensors and imaging devices
}

\author{
Delauney Laurent ${ }^{1}$, Boukerma Kada ${ }^{1}$, Bucas Karenn ${ }^{1}$, Coail Jean-Yves ${ }^{1}$, Debeaumont Mathieu ${ }^{1}$, \\ Forest Bertrand ${ }^{1}$, Garello Celia ${ }^{1}$, Guyader Gerard ${ }^{1}$, Le Bras Yves ${ }^{1}$, Peleau Michel ${ }^{1}$, \\ Rinnert Emmanuel ${ }^{1}$
}

${ }^{1}$ IFREMER, Ctr Brest, CS 10070, F-29280 Plouzane, France.

\begin{abstract}
:
Oceans environmental monitoring and seafloor exploitation need in situ sensors and optical devices (cameras, lights) in various locations and on various carriers in order to initiate and to calibrate environmental models or to operate underwater industrial process supervision. For more than 10 years Ifremer deploys in situ monitoring systems for various seawater parameters and in situ observation systems based on lights and HD Cameras. To be economically operational, these systems must be equipped with a biofouling protection dedicated to the sensors and optical devices used in situ. Indeed, biofouling, in less than 15 days [1] will modify the transducing interfaces of the sensors and causes unacceptable bias on the measurements provided by the in situ monitoring system. In the same way biofouling will decrease the optical properties of windows and thus altering the lighting and the quality fot he images recorded by the camera.
\end{abstract}


It is acknowledged that a coastal monitoring system must be able to run without maintenance for 3 months [4-5] in order for the system to be economically acceptable. For deep-sea observatories, actual maintenance interval on the Canadian Venus system is 6 months. ESONET, the European network of excellence for deep-sea observatories defines maintenance interval recommendation from 12 up to 36 months.

Protection strategies adopted by oceanographic sensors manufacturers rely on two methods [1]. One first method is classified as active and is based on wipers. This technique presents a weakness, after 1 month in sea water the material used for the wiper is getting ineffective due to its deterioration. Moreover, the design of the sensor-transducing interface must be adapted to allow the wiper to work properly, which is sometime impossible. Another technology, classified as passive consists to coat surfaces that need to be protected with copper. This technique works quite well when a close cell can be arranged around the area to be protected. But, for some measurements, for example for dissolved oxygen monitoring, copper ions can disrupt the measurement process and cause bias on the provided measurements. Recently, the Canadian company AML has proposed a UV irradiation biofouling protection scheme for sensors. The system, called UV•Xchange ${ }^{1}$, is based on UV Bulbs that irradiates the area to be protected. In some situations, where energy is not too much a concern ${ }^{2}$, this solution seems to be be a good choice.

Ifremer, in order to protect the sensors and optical devices against biofouling for the in situ oceanographic monitoring systems uses a method derived from industrial applications and based on seawater electrolysis to produce hypochloric acid [2]. This method has been

\footnotetext{
${ }^{1}$ http://www.amloceanographic.com/CTD-Sound-Velocity-Environmental-Instrumentation-Home/UVXchange

${ }^{2} \mathrm{UV} \bullet \mathrm{Xchange}$ consumption : $100 \mathrm{~mA}$ up to $190 \mathrm{~mA}(12-26 \mathrm{~V})$ depending of the version.
} 
successfully applied in various monitoring applications. For example, for the Marel or Molit monitoring systems that use a pumped circuit [5] or for autonomous and transportable systems like Marel Estran or Marel Smatch ${ }^{3}$, and for seafloor observatories [6] like Momar, Venus [7], Neptune, or Ifremer Tempo module [7] where the sensors are directly immersed in seawater without any proxies like pumping devices.

\section{Localized production of biocide from the surface of the transducing interface, the concept.}

A technique to produce a biocide in seawater as close as possible of the transducing interface is to perform in this area electrolysis of seawater. Hypochloric acid is produced at the working electrode that surrounds the transducing area of the sensor [2]. The figure below shows such protection scheme on an in situ turbidimeter. On the left side, the unprotected turbidimeter shows an important coverage of barnacles after 80 days of deployment. The protected turbidimeter, that uses a flat washer as a working electrode shows a clean transducing interface after the same deployment. As shown, this technique can be used on the sensor without modifying its design. So, it can be used on existing instruments.

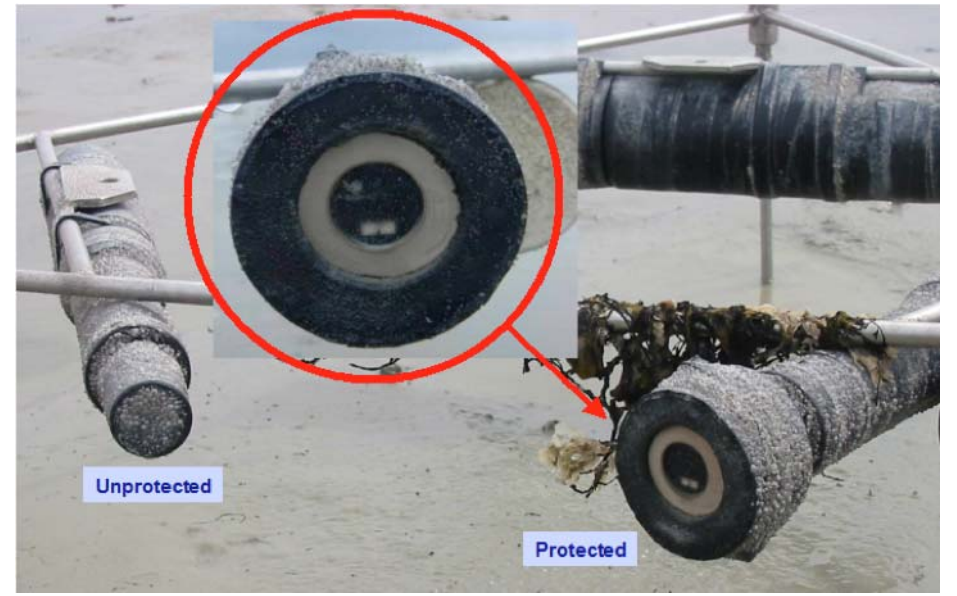

Figure 1 - Biofouling protection by seawater electrolysis on turbidimeter Mont St Michel Bay - March to May - 80 days

(Photo: Ifremer - L.Delauney)

In some applications, the adaptation to the sensor-transducing interface can be difficult. Additionally, this technique, for long-term deployment and when energy is very rare (deep sea un-cabled observatory), is still a bit consuming ( $240 \mathrm{~mW}$ ).

In the specific case of optical sensors (based on a "transparent" optical window), cameras or lights, the electrode, where the biocide generation takes place in case of seawater electrolysis, can be a conductive and transparent coating based on doped tin dioxide and sprayed straightforwardly on the optical windows of the device. Ifremer on Helgoland Island, originally, has tested this protection scheme once during summer 2005 (BRIMOM ${ }^{4}$ EU project). The figure 2 below shows biofouling colonization on the unprotected instrument and a successful protection of the optical window of the protected instrument.

\footnotetext{
${ }^{3}$ Nke products Ifremer licenced - http://www.nke-instrumentation.com/products/networks/estuary-zone.html

4 EC proposal EVR1-2001-00034 ; Biofouling Resistant Infrastructure for Measuring, Observing and Monitoring
} 


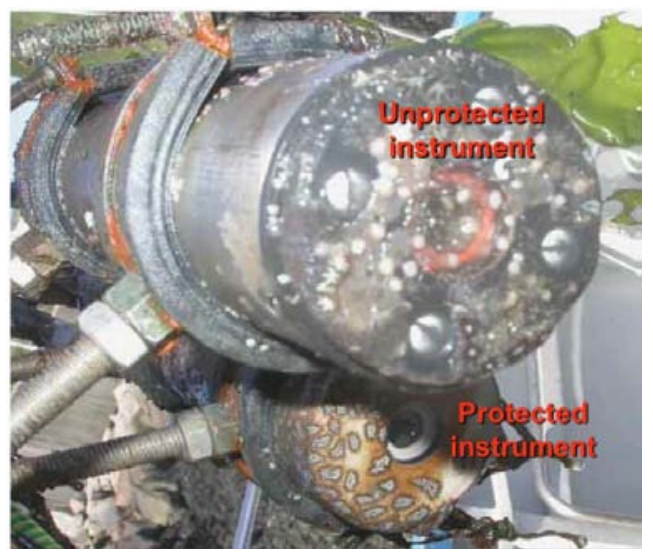

\section{Figure 2}

Biofouling protection of a fluorometer by seawater electrolysis on a conductive transparent layer Helgoland - June to September - 70 days

(Photo: Ifremer - L.Delauney)

This in situ test has been the first example of an optical sensor effectively protected by local chlorination based on a conductive coating on its optical windows. This technique offers a high level of robustness (no moving parts), a high level of integration and uses 20 times less energy than the conventional method based on titanium electrode. It has the advantage to be an active technique that can be turned ON and OFF in order to arrange free biocide generation period.

\begin{tabular}{ll}
\hline Level & Description \\
\hline TRL 1 & Basic principles of technology observed and reported \\
\hline TRL 2 & Technology concept and/or application formulated \\
\hline TRL 3 & Analytical and laboratory studies to validate analytical predictions \\
TRL 4 & Component and/or basic sub-system technology valid in lab environment \\
\hline TRL 5 & Component and/or basic sub-system technology valid in relevant environment \\
TRL 6 & System/sub-system technology model or prototype demo in relevant environment \\
TRL 7 & System technology prototype demo in an operational environment \\
TRL 8 & System technology qualified through test and demonstration \\
TRL 9 & System technology qualified through successful mission operations \\
\hline
\end{tabular}

Figure 3 - TRL, Technology Readiness Level used for oceanographic instrumentation development Source: Nexos ${ }^{5}$ EU project, based on successive evolutions of TRL concept [11] [12].

In terms of Technology Readiness Level, c.f. figure 3, this technique has been designed at a laboratory stage, TRL 4, many years ago. Then, one in situ test has been successfully performed for approaching the TRL 5. But, to reach TRL 7 and above, operational and production aspects was needed to be treated. One of the main issues concerned the study of the aging of the tin dioxide coating and additional in situ tests.

\section{Technological description of biofouling protection by electrolysis on conductive layer for optical windows.}

The process requires on the surface of the glass window the deposit of a conductive and transparent film of tin dioxide $\left(\mathrm{SnO}_{2}\right)$ whose physicochemical characteristics have been optimized by the French CNRS-LISE UPR15 laboratory in collaboration with the Ifremer

\footnotetext{
${ }^{5}$ NeXOS - Next generation Low-Cost Multifunctional Web Enabled Ocean Sensor Systems Empowering Marine, Maritime and Fisheries Management, is funded by the European Commission's 7th Framework Programme Grant Agreement No 614102
} 
Technological Research Group in Brest [9] [10]. The conductive layer has been optimized and is used as an anode, polarized at a specific potential, to produce chlorine. The biocide action is essentially based on the electrochemical generation of hypochloric acid capable of preventing the development of the biofilm. The $\mathrm{SnO}_{2}$ film deposition on the window is obtained by pyrolysis of a first aerosol $\mathrm{SnCl}_{4}+\mathrm{NH}_{4} \mathrm{~F}$ for film F-doped and then a second aerosol $\mathrm{SnCl}_{4}+\mathrm{SbCl}_{3}$ for film Sb-doped, to $545^{\circ} \mathrm{C}$. Then an electro deposition of metallic copper on the edge of the window is performed that will allow establishing the necessary electrical contact to the $\mathrm{SnO}_{2}$ coating.
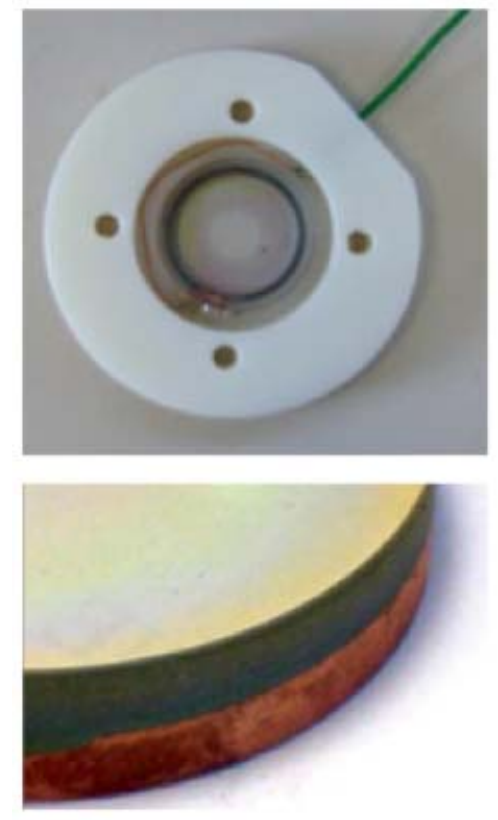
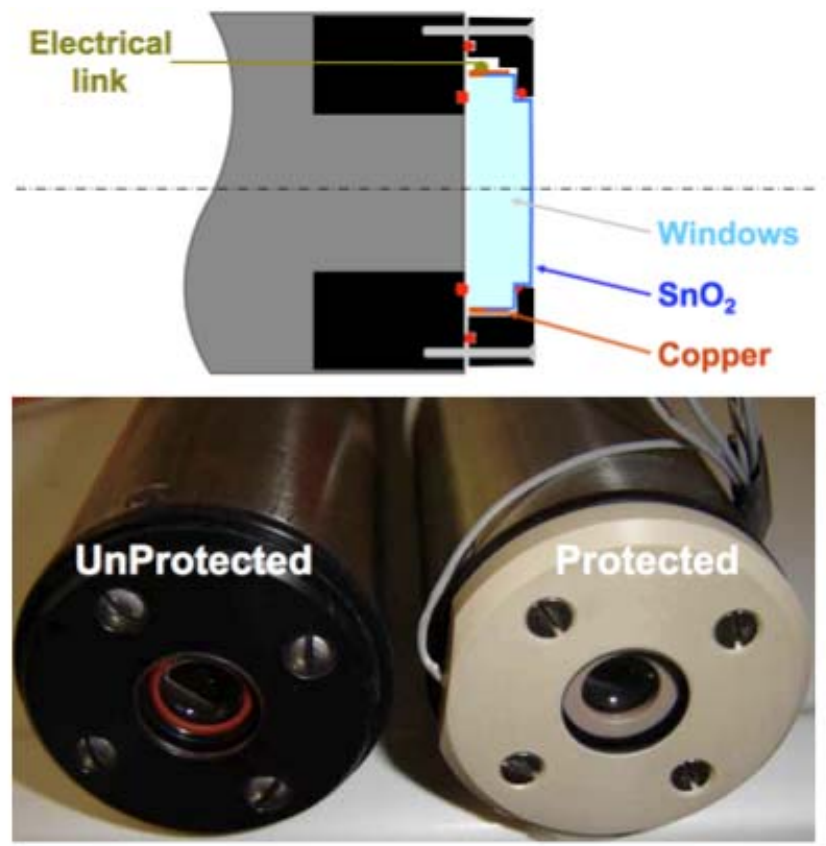

Figure 4: Left: Functionalized window with $\mathrm{SnO}_{2}$ doped conductive coating and copper deposit on the edge Right: Window arrangement on TriOS microFlu-chl.

(Photo: Ifremer - L.Delauney - Y.Le Bras)

The functionalized window is used on the instrument instead of the original one. The holder of the porthole must be adapted to allow an electric wire to be connected to the edge of the window on which is the deposition of copper. This electrical wire is then connected to the electronic unit that will polarize the $\mathrm{SnO}_{2}$ coating. The electronic unit can take place inside the instrument (schematic shown on upper right figure 4) or outside the instrument (schematic shown on lower right figure 4). The polarization is connected to a Zinc reference electrode and a counter electrode to function properly. These electrodes are placed on the instrument itself or on the outside polarization unit container. The current drawn by the whole system is not more $1 \mathrm{~mA}$ and can be powered by a $12 \mathrm{~V}$ supply. Then the protection scheme needs around $15 \mathrm{~mW}$ to be effective.

\section{Aging tests in seawater of tin oxide conductive coating.}

\section{○ Testing bench, tests and tools}

Despite this successful in situ test to protect a fluorometer for nearly 2 months, the aging of the tin dioxide coating must be known in order to support long-term deployment up to 3 years and to be compatible with economical aspect for oceanographic sensors manufacturers. 
Then, the aging of the tin dioxide coating has been studied in term of electrochemical behaviour and material modifications all along a nearly 3 years of biocide production in seawater.

To perform this aging test, $12 \mathrm{SnO}_{2}$ portholes have been evaluated in a testing tank (figure 5) with a continuously renewed seawater environment. A chlorination module polarized the 12 windows and an acquisition unit was measuring continuously, on each porthole, 2 potentials and 1 current. They are: the potential on the working electrode (WE) versus reference electrode (REF), the potential on the counter electrode (CE) versus reference electrode (REF), and, the current from the working electrode (WE, tin oxide conductive layer).
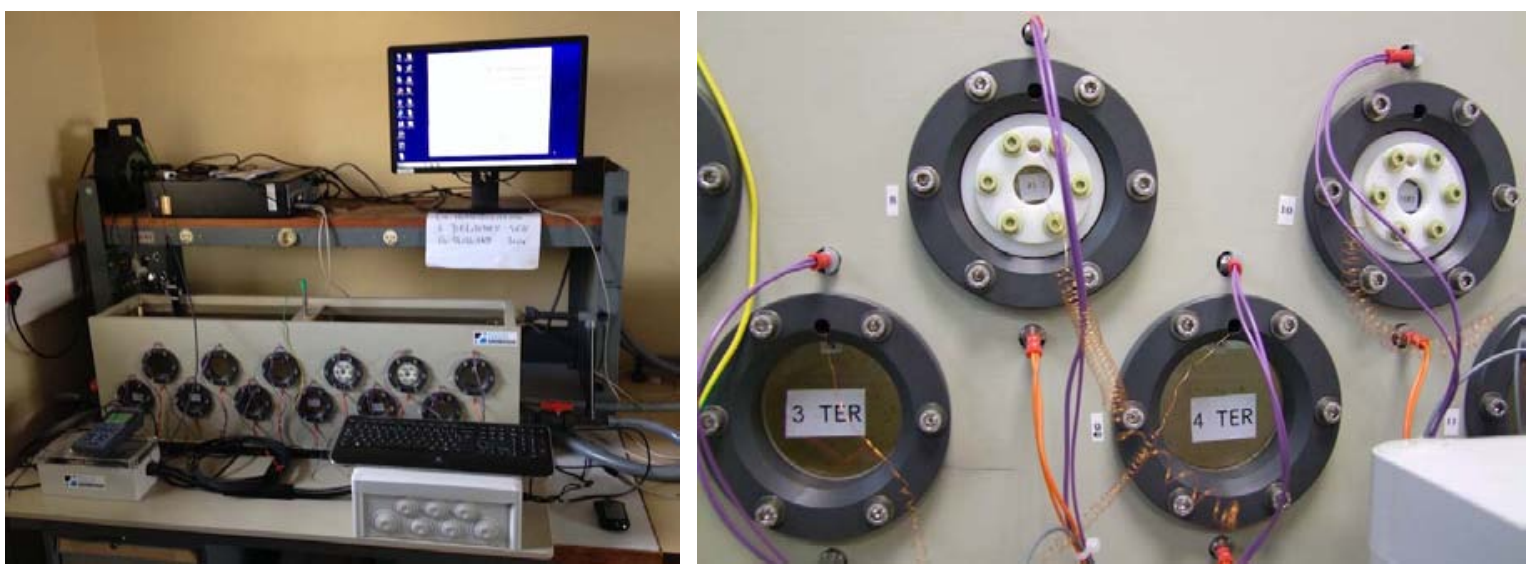

Figure 5: Tin oxide conductive coating aging test bench.

Tank, continuous renewal in seawater, polarization module, control and acquisition system (Photo: Ifremer - L.Delauney - Y.Le Bras)

Data processing software (Figure 6) has been specifically developed by Ifremer Technological Research Unit to facilitate the review of the current and potential data recorded for nearly 3 years. It allows to sort data when the windows are polarised (B) and when the windows are not polarised (C).

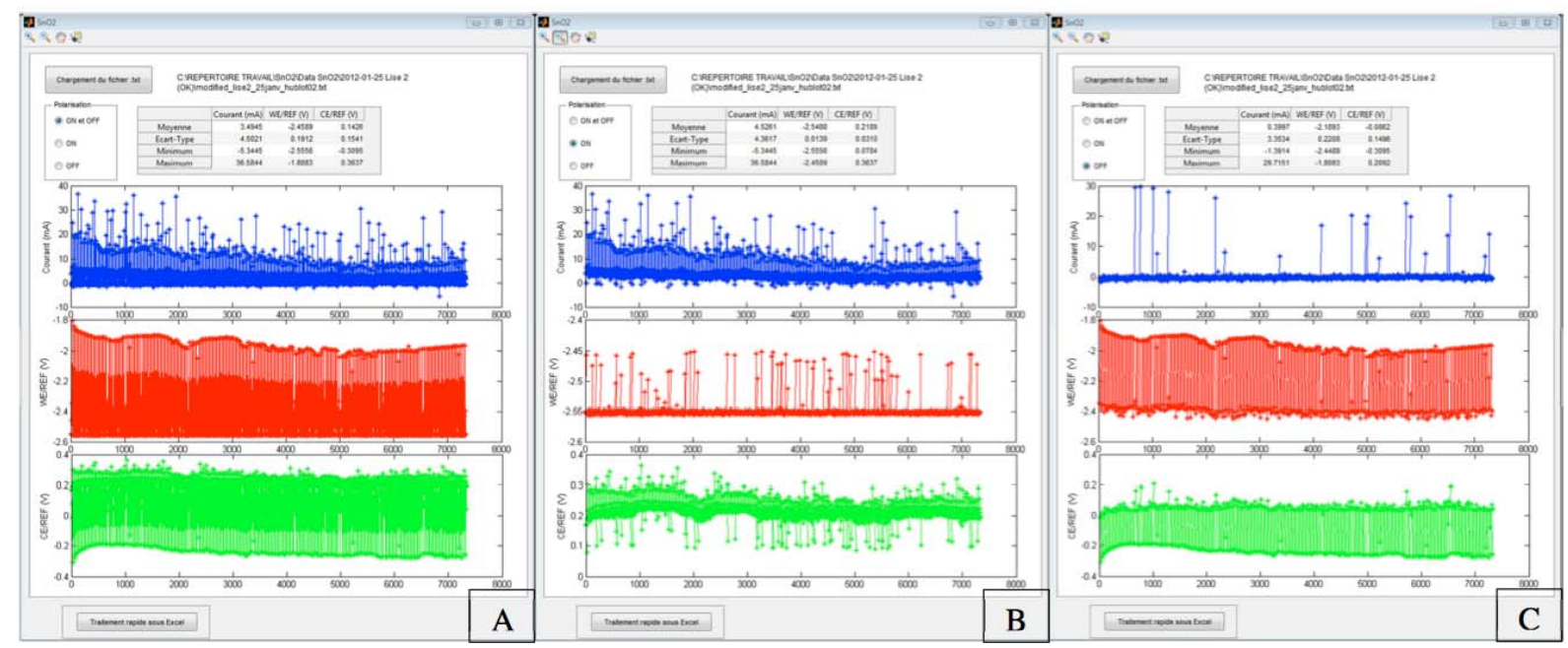

Figure 6: Tin oxide conductive layer aging test data processing software.

A: polarisation On and Off ; B: Polarisation On; C: Polarisation Off.

The thicknesses of the $\mathrm{SnO}_{2}$ conductive layers have been measured on all the 12 windows before and periodically during the aging test. At the same time, an electrochemical test (I/V in 
$\mathrm{NaCl} 0.5 \mathrm{M}$ ) was performed on every window (measurement performed by the CNRS-LISE UPR15 laboratory).

\section{○ Aging test results}

For more than 2 years and a half and for the 12 windows, the polarization currents in natural seawater remained between 0.8 and $1.2 \mathrm{~mA}$.

The two potentials controlled by the acquisition system (WE/REF and CE/REF) did not show important variation except the ones due to seawater conductance evolution according to temperature.

The thickness of the $\mathrm{SnO}_{2}$ conductive layers on 8 windows that were sampled from the testing bench has not changed $(700+/-50 \mathrm{~nm}$ in average).

The electrochemical tests (I/V in $0.5 \mathrm{M} \mathrm{NaCl}$ electrolyte) performed on 4 windows every year show unchanged behaviours.

And, even if this testing bench was not designed to test biofouling protection efficiency, we were very pleased to observe that the protected portholes tested in natural seawater in the test tank show no biofouling while the walls of the test tank, made of PVC, and the window without $\mathrm{SnO}_{2}$ coating were covered with an organic deposit.

\section{In situ test of biofouling protection by electrolysis on conductive layer for optical windows}

Three TriOS microFlu-chl sensors have been used to test the efficiency of the biofouling protection by conductive layer on optical windows. These sensors are convenient for such experiment since the porthole can be easily dismantled without disassembling the whole instrument.

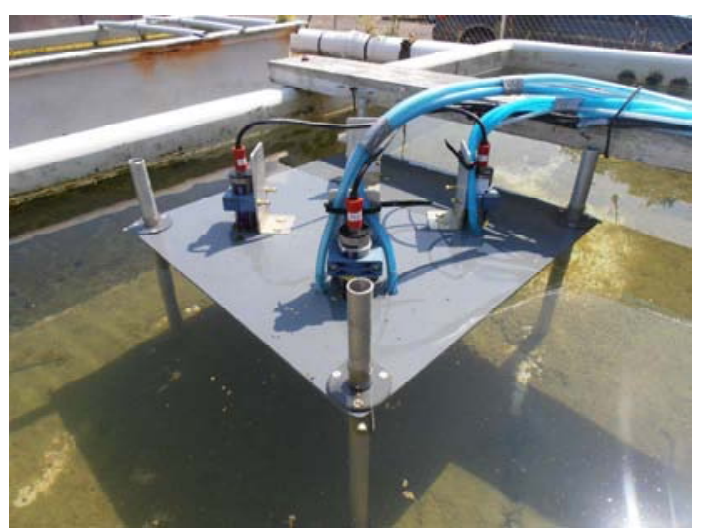

Figure 7: In situ testing bench for biofouling protection efficiency.

(Photo: Ifremer - L.Delauney)

The Ifremer in situ testing facilities has been used to performed the experiment. A seawater continuous renewed testing tank was equipped with a sensors testing bench for the 3 tested sensors (figure 7). The 3 sensors were connected to an acquisition device in order to continuously record the measurement produced. Real time monitoring was possible since the acquisition system was connected to the internal Ifremer network. 
As a first step, the 3 fluorometers have been calibrated at the Ifremer Metrological Calibration Laboratory in order to adjust the voltage signal produced by the sensors. A natural algae culture has been used as a "standard" solution to calibrate the sensors.

In July 2014, the 3 fluorometers without any biofouling protection have been placed on the in situ testing bench. This experiment was meant to evaluate their sensibility to biofouling and to the biofouling development severity of the in situ testing site. The results obtained are shown on figure 8.

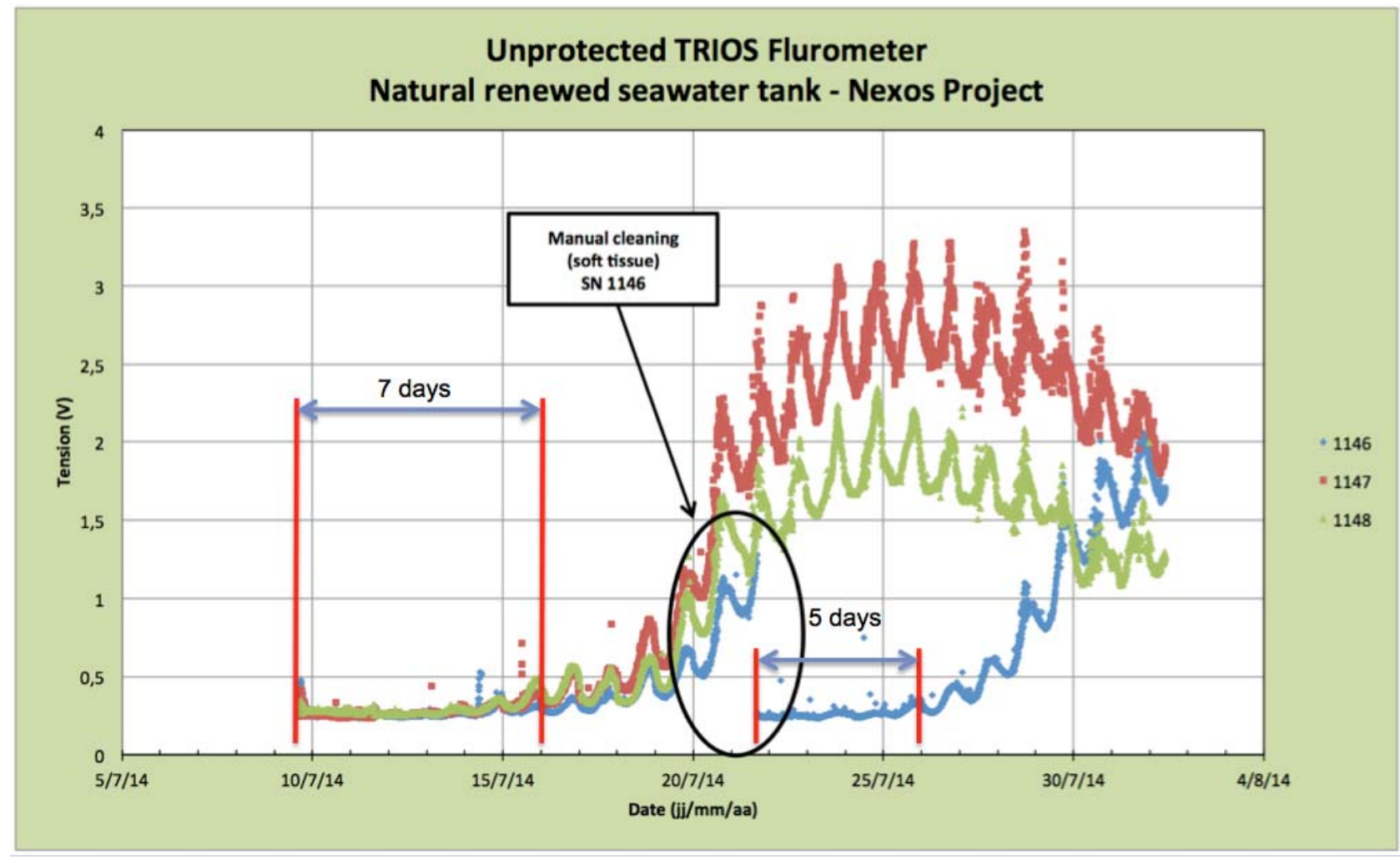

Figure 8: Effect of biofouling on three unprotected fluorometer sensors

(Ifremer in situ testing bench)

The three sensors referenced 1146, 1147 and 1148 shows a positive drift after 7 days of exposure. In order to identify the cause of the drift, the fluorometer window " 1146 " has been manually cleaned. As shown on figure 8 , the signal of the 1146 sensor instantly came back to the original measurement before the suspected drift. Then, 5 days after cleaning, sensor "1146" started to drift with a similar drift slop and evolution than originally observed.

Due to a technical error, fluorometer "1146" gets a leak that resulted in seawater inside the instrument. Then, fluorometer " 1146 " has been replaced by fluorometer " 1241 ".

Fluorometer "1148" and "1241" have been equipped with tin oxide protected windows and polarization systems. The calibration of these protected instruments shown an $8 \%$ decrease of the sensibility that has been compensated by data post processing.

The in situ test has started in September 2014 and is still running in April 2015. It's now for 8 months that the tin oxide biofouling protection is showing a good efficiency against this reasonable biofouling impact. Indeed, the biofouling effect obtained in the In situ testing bench (figure 7) is not as severe as the one we could obtain in open sea condition. But, 
nevertheless, it has been demonstrated (figure 8) that fouling obtained in such situation can disrupt the fluorescence measurements in less than 7 days.

Figure 9 shows in red the unprotected fluorometer signal (1147), in blue and green the tin oxide protected fluorometer signals $(1148,1241)$. Additionally, in purple, we can see the fluorescence real time measurements produced by the Iroise Marel buoy ${ }^{6}$ situated in the open sea close to the in situ testing bench. These open sea Chl-a measurements show that we do not miss big fluorescence events and that the drift observed on the unprotected instrument is not a fluorescence event. We can see that slight fluorescence variations observed in open sea by the Marel Buoy are a bit filtered by the in situ testing bench protocol (seawater pumping and distribution).

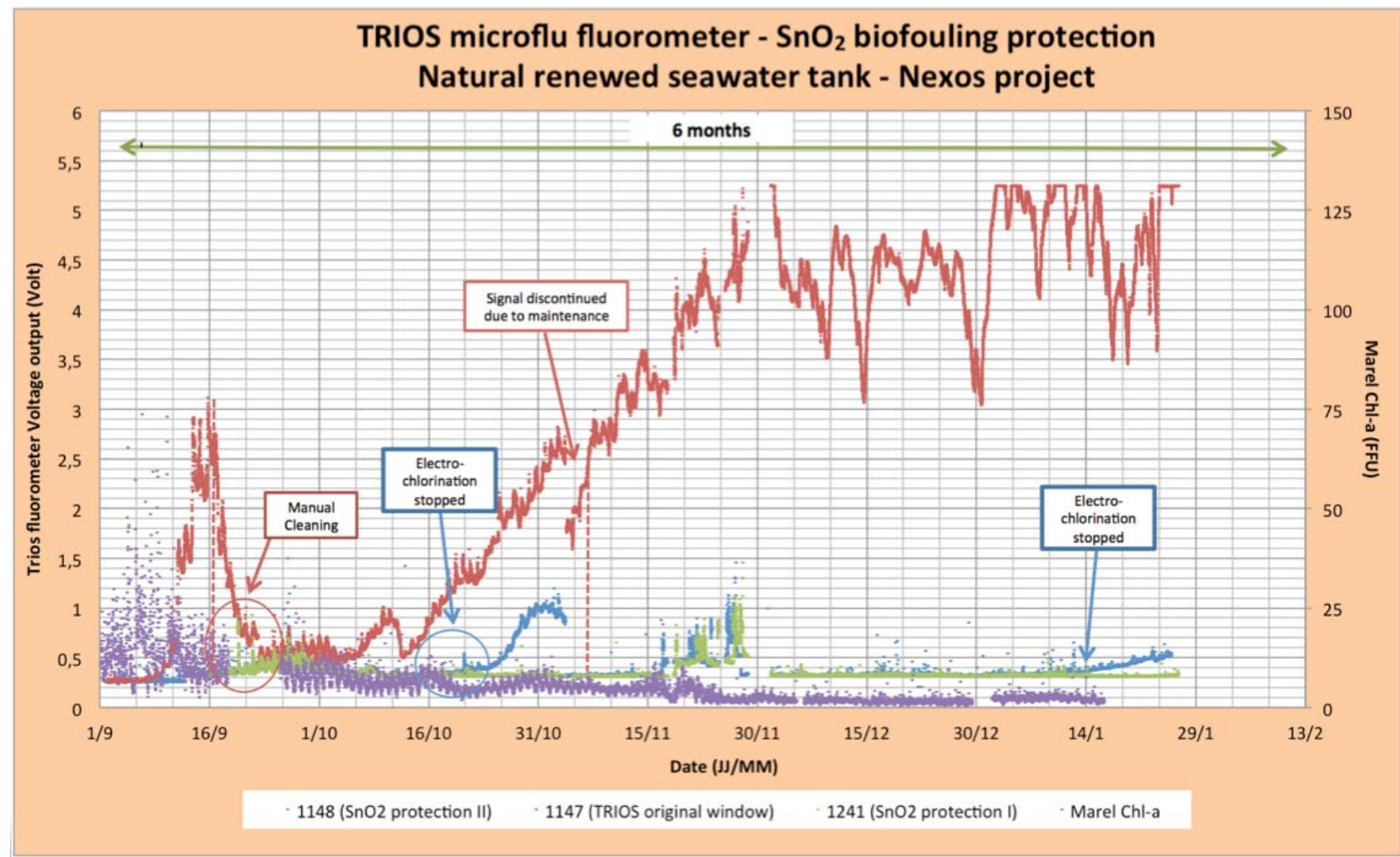

Figure 9: Tin oxide conductive layer biofouling protection efficiency test on fluorometer sensors

(Ifremer in situ testing bench)

Figure 9 shows a drift of the unprotected instrument (1147-red) after 7 days of in situ measurement ( $7^{\text {th }}$ of September). After nearly 2 weeks ( $21^{\text {st }}$ of September) as the sensor 1147 was giving unstable measurements, it has been manually cleaned in order to ensure that the unstable signal was due to fouling deposits on the windows. After cleaning, as shown on figure 9, the signal returned to conventional value in comparison to the two others protected sensors (1148-blue and 1241-green). After another 13 days of measurement ( $6^{\text {th }}$ of October), the unprotected instrument (1147-red) started again to drift.

During this period, from $1^{\text {st }}$ of September up to $10^{\text {th }}$ of October, the two protected sensors (1148-blue and 1241-green) did not show any suspicious drift. It shows that the biofouling protection seems to work. On $21^{\text {st }}$ of October it was decided to stop the electro-chlorination

\footnotetext{
${ }^{6}$ http://www-iuem.univ-brest.fr/observatoire/observation-cotiere/parametres-physico-chimiques/testpeg
} 
on the protected instrument 1148-blue. 5 days later fluorescence signal started to drift whereas the protected fluorometer (1241-green) remained at a conventional fluorescence level according to the Marel Chl-a results. Consequently, we can consider that the biofouling protection on the protected fluorometer 1241-green has been efficient from $1^{\text {st }}$ of September up to $21^{\text {st }}$ of October.

Then, the sensor 1148-blue was cleaned manually in order to return at the reference state. Following this, we can see that both protected sensors (1148-blue and 1241-green) remained in coherence with measurements of the Marel buoy, showing no apparent drift for 5 months. At this point of the test, we decided again to stop the chlorination on sensor 1148-blue. And again, the signal of this sensor started to drift whereas the signal of the protected one remained stable and in coherence with the Marel buoy measurements. On figure 9 we can see, that, beyond this last intervention on sensor 1148, the biofouling protection on 1241-green sensor is efficient in this testing condition and for 7 months, from $1^{\text {st }}$ of September up to the end of March. These results are very encouraging.

\section{Conclusion and discussion on biofouling protection by electrolysis on conductive layer for optical windows}

The aging in seawater of the conductive coating has been studied for 3 years and is showing no variations for the thickness and for the electrolysis behaviour. Key potentials and exchanged current has been monitored during these 3 years, no important variation has been observed except the ones due to seawater conductance evolution according to temperature. These results are crucial and will allow considering using this technique for operational purpose and in collaboration with optical sensors manufacturers and optical devices (camera and lights) manufacturers.

This biofouling protection scheme can be used on optical devices that use glass windows as transducing interfaces. It is not possible to use it on optodes based on transducing foils as the $\mathrm{O}_{2}$ or $\mathrm{CO}_{2}$ sensors.

The response time of the sensors is not affected by the protection scheme; every calibration that has been conducted on the sensors did not show any response time variation. Nevertheless, an $8 \%$ sensitivity reduction is observed for Chl-a sensors. This disadvantage is under investigation and a solution has been found. Further studies are needed about it and will be performed all along the Eu Nexos project that end in 2017.

Chlorine is generated in such small amount that it is not possible to measure it by colorimetric method. Consequently, we are very confident on the effect that chlorine could have on the sensors parts as rubber ring or plastic window holder. In addition, Ifremer uses for many years localised chlorination to protect sensor-transducing interface from biofouling [1] [2], and no damaged has been observed on the sensor due to the chlorine production that takes place in much larger quantities than the method proposed here.

The spraying station used to produce the "functionalized" optical windows is actually a laboratory device that has been setup internally at Ifremer. In order to organize the use of this protection method by sensors manufacturers and optical devices (camera and lights) manufacturers, the spraying machine will need to be transferred to a company in charge of producing the functionalized windows. This is a delicate aspect of the future of the project since oceanographic instruments dedicated to long term deployments is still a niche market. 
Biofouling protection by conductive layer on optical windows has now a Technological Readiness Level equals to 6 . Indeed, the protection has been tested with success on 2 prototypes in a relevant environment (Ifremer in situ testing bench). To reach the next level, this protection method must be tested in open sea. In the Nexos EU project, it is plan to deploy the protected instruments close to the Iroise Marel buoy and then on the EMSO Molene coastal seafloor observatory ${ }^{7}$.

\section{AKNOWLEDGEMENTS}

The authors would like to thanks the French Carnot ANR grant agreement and the EU NEXOS project grant agreement for the inestimable help to fund these research works.

\section{REFERENCES}

[1] Delauney L., Compère C., Lehaitre M., Biofouling protection for marine environmental sensors, Ocean Science, 6(2), 503-511, ISSN: 1812-0784 - 2010

[2] Delauney L., Compère C., Biofouling protection for marine environmental sensors by local chlorination, Springer Series on Biofilms vol. 4, Marine and Industrial Biofouling, pp119-134, 2009

[3] M.Lehaitre, L.Delauney and C. Compère, Biofouling and underwater measurements pp463-494 Real-time coastal observing systems - UNESCO 2008 - ISBN 978-92-3-104042-9

[4] Woerther P., Grouhel A. (1998) Automated measurement network for the coastal environment. OCEAN'S 98 IEEE-Conference Proceedings, 2, p 1149-1154

[5] Woerther P. (1999) Coastal environment of the Seine bay area monitored by a new French system of automated measurement stations. EUROGOOS, Second International Conference Proceeding, p 255264

[6] Y. Auffret, J. Blandin, D. Choqueuse, C. Compère, L.Delauney, J.F. Drogou, P. Jégou, C. Lévêque, J.F. Drogou, J.F. Rolin, P. Valdy - Long-term subsea observatories: architecture comparison, infrastructure design, interfaces, materials, sensor protection and deployment operations, Springer Praxis Book, January 2010 - 1st Edition., 2011, 500 p., Hardcover, ISBN: 978-3-642-11373-4.

[7] Sarrazin J., Blandin J., Delauney L., Dentrecolas S., Dorval P., Dupont J., Legrand J., Leroux D., Leon P., Leveque J-P., Rodier P., Vuillemin R., Sarradin P-M. (2007) TEMPO: a new ecological module for studying deep-sea community dynamics at hydrothermal vents. In OCEAN'S 07 IEEE-Aberdeen Conference Proceedings, p 1-4

[8] VENUS Newsletter, Volume 19 - Summer/Fall 2008, New and Improved: http://venus.uvic.ca/resources/documents/2008SummerNewsletter.pdf

[9] Patent WO 2004069645 A1 - Method for production of an anti-fouling protective coating on a support and corresponding support.

[10] Debiemme-Chouvy, Y. Hua, F. Hui, J.-L. Duval, D. Festy, H. Cachet (2011) Electrochemical treatments using tin oxide anode to prevent biofouling, Electrochimica Acta 56 (2011) 10364- 10370

[11] Ralph D.Prien, "The future of Chemical in-situ sensor", Marine Chemistry vol.107, pp 422-432, 2007.

[12] C. Waldmann, M. Tamburri, R. D. Prien, P. Fietzek "Assessment of sensor performance" Ocean

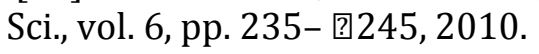

\footnotetext{
${ }^{7}$ http://www.emso-eu.org/infrastructure/emso-sites-description.html?id_site=8
} 